\title{
MORFO-ANATOMIA DO FRUTO E SEMENTE DE Oenocarpus minor Mart. (ARECACEAE) ${ }^{1}$
}

\author{
MARIA SILVIA DE MENDONÇA², ANDRÉIA BARRONCAS DE OLIVEIRA³, MARIA GRACIMAR \\ PACHECO DE ARAÚJO ${ }^{4}$, LÍDIA MEDINA ARAÚJO ${ }^{5}$
}

\begin{abstract}
RESUMO - Foi feita a caracterização morfo-anatômica de frutos e sementes de Oenocarpus minor Mart. Frutos maduros foram coletados de vários indivíduos, em floresta densa antropizada no município de Itacoatiara, Amazonas. Foram feitas mensurações de tamanho, do peso do fruto e da semente e grau de umidade da semente. $\mathrm{O}$ estudo anatômico foi feito pelo método de inclusão em parafina. Foi feito um estudo complementar da análise de sais minerais do fruto pelo método de digestão ácida. O fruto é séssil, monospérmico, variando de globoso-ovóide a elipsóide, com epicarpo fino, coriáceo e glabro, formado por uma epiderme de células cutinizadas e região subepidérmica com células taníferas de diferentes formas. Mesocarpo fibro-carnoso e oleaginoso constituído por idioblastos taníferos, freqüentemente agrupados, entre células parenquimáticas. Feixes fibrovasculares localizam-se entre o mesocarpo e o endocarpo. Endocarpo fibroso, delimitado pela epiderme locular composta de uma única camada de células esclerificadas. Semente de globosa a elipsóide, com tegumento fino, formado por várias camadas de células taníferas; com endosperma sólido e homogêneo, com células longas de paredes espessas. Embrião do tipo capitado. A análise dos componentes minerais da polpa apresenta $0,67 \mathrm{mg} / \mathrm{g}$ de $\mathrm{Ca}, 0,43 \mathrm{mg} / \mathrm{g}$ de $\mathrm{Mg}, 0,08 \mathrm{mg} / \mathrm{g}$ de Fe, $0,02 \mathrm{mg} / \mathrm{g}$ de $\mathrm{Cu}, 9,5 \mu \mathrm{g} / \mathrm{g}$ de $\mathrm{Zn}$ e $0,02 \mathrm{mg} / \mathrm{g}$ de $\mathrm{Mn}$.
\end{abstract}

Termos para indexação: morfologia, palmeira, bacabinha.

MORPHO-ANATOMY OF THE FRUIT AND SEED OF Oenocarpus minor Mart. (ARECACEAE)

ABSTRACT - The morpho-anatomical characterization of fruits and seeds of Oenocarpus minor Mart. Ripe fruits were collected from several individuals, in dense forest disturbed in the municipality of Itacoatiara, State of Amazonas. Measurements of size and weight of the fruit and seed were taken as well as the humidity degree of the seed. The anatomical study was performed by the method of paraffin inclusion. An additional study of the mineral salts analysis of the fruit was also performed by the method of acid digestion. The fruit is sessile, one-seeded, varying from globular-ovoid to ellipsoid, with thin, coriaceous and glabrous epicarp, formed by an epidermis of cutinized cells and subepidermal region with tanniferous cells of different shapes. The mesocarp is fibro-fleshy and oleaginous, consisting of tanniferous idioblasts frequently grouped among parenchyma cells. Fibrovascular bundles are located between the mesocarp and the endocarp. Fibrous endocarp, delimited by the locule epidermis composed by only one layer of sclerified cells. Seed from globular to ellipsoid in shape, with thin tegument made of several layers of tanniferous cells; with solid and homogeneous endosperm, formed by long cells with thick walls. Capitate embryo. The analysis of the mineral components of the pulp presented $0.67 \mathrm{mg} / \mathrm{g}$ Ca, $0.43 \mathrm{mg} / \mathrm{g} \mathrm{Mg}, 0.08 \mathrm{mg} / \mathrm{g} \mathrm{Fe}, 0.02 \mathrm{mg} / \mathrm{g} \mathrm{Cu}, 9.5 \mu \mathrm{g} / \mathrm{g} \mathrm{Zn}$ and $0.02 \mathrm{mg} / \mathrm{g} \mathrm{Mn}$.

Index terms: morphology, palm, Oenocarpus.

${ }^{1}$ Submetido em 19/03/2007. Aceito para publicação em 16/11/2007.

2Prof. Titular, Dra. LABAF/FCA/UFAM, msilvia@ufam.edu.br;

${ }^{3}$ M.Sc. em Botânica; LABAF/FCA/UFAM; Rua Damasco n. 24 quadra 24 Conj. Campos Elíseos - Planalto, 69045-070, Manaus-Am, andreiabo@hotmail.com;
${ }^{4}$ Dra. em Botânica; LABAF/FCA/UFAM, mgaraujo@ufam.edu.br;

${ }^{5}$ Doutoranda em Biotecnologia; Departamento de Química/UFAM, lídia@ufam.edu.br. 


\section{INTRODUÇÃO}

Oenocarpus minor é uma palmeira de subdossel, distribuída no Norte da América do Sul, ocorrendo geralmente em terra firme da Floresta Tropical Úmida (Henderson \& Scariot, 1993), com floração e frutificação nos meses de novembro a abril. Trata-se de uma espécie conhecida popularmente como bacabinha, de frutos comestíveis dos quais se faz uma deliciosa bebida, muito apreciada pelos nativos da região amazônica.

A morfologia dos frutos, sementes e plântulas de palmeiras vêm sendo estudadas por vários autores, desde trabalhos mais abrangentes como Tomlinson (1960), Uhl \& Dransfield (1987) a estudos específicos abordando outras espécies (Mendonça, 1996; Araújo et al., 2000, Aguiar \& Mendonça, 2003 e Araújo, 2005). Entretanto, a morfo-anatomia do grupo ainda é pouco conhecida havendo a necessidade de se estudar um maior número de espécies. Investigações a respeito das estruturas reprodutivas destas plantas são necessárias para contribuir com programas de conservação dos ecossistemas amazônicos e manutenção dos recursos naturais, além de disponibilizar informações para os estudos taxonômicos e fisiológicos. O presente trabalho descreve a morfo-anatomia dos frutos e sementes de Oenocarpus minor, complementando com informações sobre a presença de macro e micro minerais.

\section{MATERIAL E MÉTODOS}

Frutos maduros da espécie foram coletados de cinco indivíduos na área de exploração da Empresa Madeireira Itacoatiara LTDA, no município de Itacoatiara, Amazonas, utilizando-se 100 unidades, para a caracterização morfológica dos frutos e das sementes, observando-se a forma, coloração, textura, as medidas do fruto (comprimento e diâmetro) e o peso da matéria fresca. As sementes foram avaliadas quanto ao tamanho, peso da matéria fresca e peso da matéria seca. Para obter o peso da matéria seca, foi utilizada uma estufa regulada a $105^{\circ} \mathrm{C}$ até peso constante para cada semente. As medidas de tamanho foram efetuadas com auxílio de um paquímetro digital e o peso com auxílio de uma balança eletrônica. Trinta sementes foram abertas para descrever a morfologia interna e retirar o embrião, que foi avaliado quanto à forma, tamanho, coloração e posição.

A umidade foi determinada em base úmida e o grau de umidade das sementes foi obtido pela equação: $\mathrm{P}_{1}-\mathrm{P}_{2} / \mathrm{P}_{1}(100)$ $=\mathrm{U}$, onde: $\mathrm{P}_{1}$ (peso da matéria fresca); $\mathrm{P}_{2}$ (peso da matéria seca); U (umidade) de acordo com Lara et al. (1976).

Para o estudo anatômico, o material foi desidratado em série alcoólica/butílica, incluído em parafina e seccionado em micrótomo rotativo. As secções histológicas foram coradas com azul de astra e safranina, e montadas em lâminas de vidro com bálsamo do Canadá, de acordo com técnicas usuais, descritas em Patiño (1986).

A metodologia utilizada para determinação dos macro e micro minerais dos frutos foi a recomendada pela AOAC (1995). O epicarpo e mesocarpo separados das sementes (20 unidades) foram acondicionados em placas de petri e congelados no freezer $\mathrm{a}-19^{\circ} \mathrm{C}$ por 24 horas. Posteriormente, os mesmos foram liofilizados em aparelho Christ Beta, modelo 1-8 LMC-1, por dois dias, macerados e peneirados até a obtenção de um material totalmente pulverizado. As amostras pulverizadas foram submetidas à digestão ácida, que consiste na pesagem de $0,5 \mathrm{~g}$ (triplicatas) dos mesmos, em um tubo digestor, adicionado $10 \mathrm{ml}$ de ácido nítrico concentrado e $2 \mathrm{ml}$ de peróxido de hidrogênio. Foi feito o aquecimento em placa digestora a $150^{\circ} \mathrm{C}$ até eliminação total dos compostos orgânicos e obtenção da solução contendo os minerais solubilizados. Após solubilização, foram diluídas com água deionizada em balão volumétrico de $100 \mathrm{ml}$ e realizada a leitura no espectrofotômetro de absorção atômica chama/ar-acetileno modelo AAS 3300Perkin elmér, previamente calibrado com soluções padrão para cada elemento. Os resultados foram expressos em $\mathrm{mg} / \mathrm{g}$ e $\mu \mathrm{g} / \mathrm{g}$. Os elementos $\mathrm{Ca}$ e $\mathrm{Mg}$ foram complexados após a diluição com óxido de lantânio, para reduzir a presença dos interferentes químicos.

As ilustrações do estudo anatômico foram obtidas por máquinas fotográficas PENTAX PZ-10 e estereoscópio ZEISS acoplado à câmera MC-80 DX.

\section{RESULTADOS E DISCUSSÃO}

O cacho de frutos de $O$. minor possui forma hiperiforme, lembrando um rabo de cavalo, com aproximadamente 28 ráquilas, cada uma contendo cerca de 35 frutos, apresentando no total, cerca de 1078 frutos por cacho (Figura 1A-B).

$\mathrm{O}$ fruto é séssil com perianto persistente e estigma residual na região apical, monospérmico e indeiscente (Figura 1C), semelhante aos frutos da maioria das espécies de palmeiras, porém, diferindo do fruto de Socratea exorrihza (Mart.) H. Wendl. (Menezes, 2000), que quando totalmente maduro é deiscente. A forma varia de globosa-ovóide a elipsóide (Figura 1C), medindo em média, 16mm de comprimento e $13 \mathrm{~mm}$ de diâmetro, com peso médio de 1,6g (Tabela 1).

Pericarpo pouco espesso em relação à semente, medindo aproximadamente 2,2 $\mathrm{mm}$ de espessura. Em Euterpe oleracea Mart. apresenta cerca de $1 \mathrm{~mm}$ de espessura, avaliado por Paula (1975). Epicarpo fino com textura coriácea e 

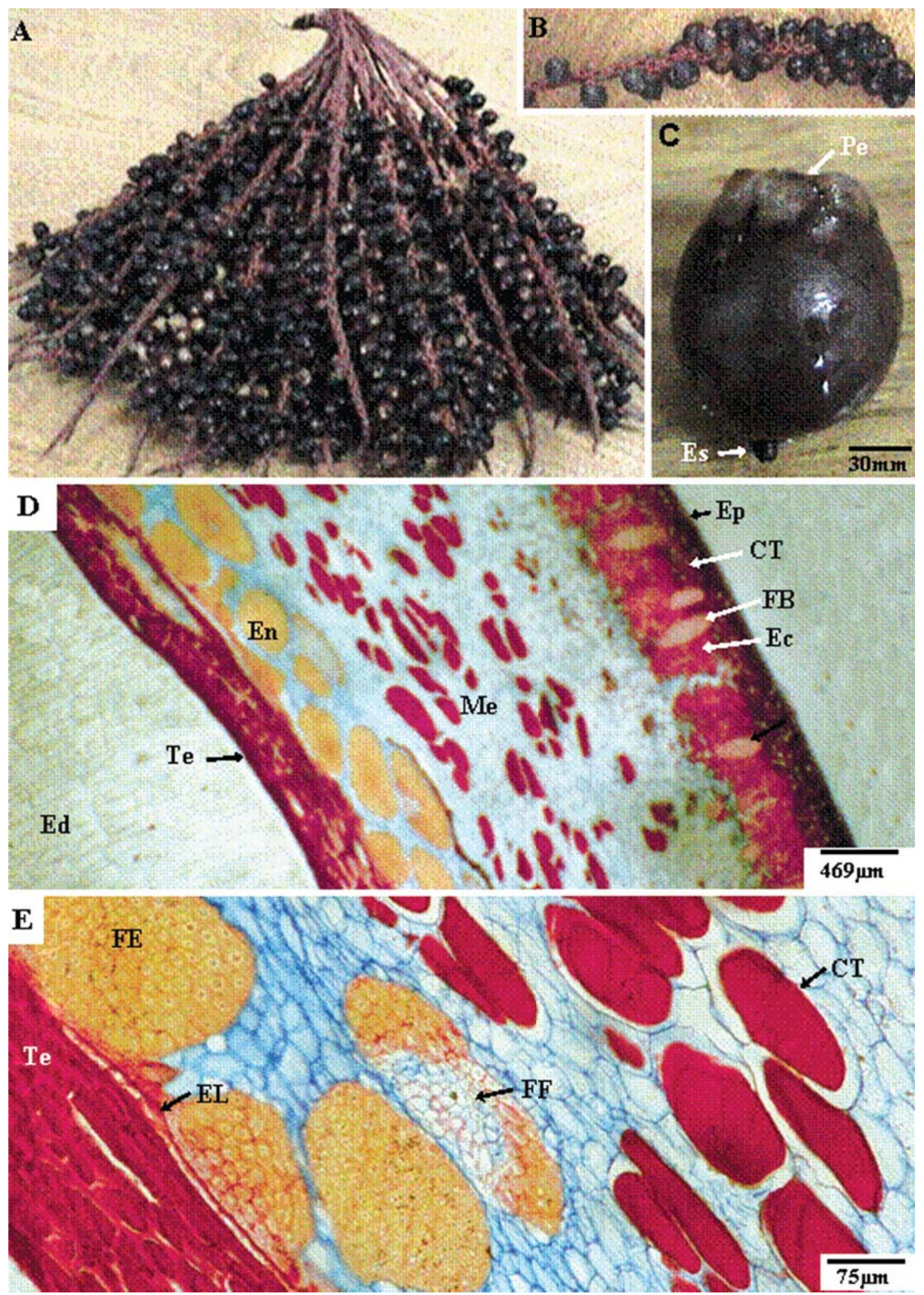

FIGURA 1. Frutos de Oenocarpus minor Mart.: A-cacho de fruto; B-ráquila; C-fruto maduro; D e E-cortes transversais do fruto, corados com safranina e azul de astra. Legenda: CT- células taníferas; EL-epiderme locular; Ec-esclereide; Ed-endosperma; Em-endocarpo; Ep-epicarpo; Es-estigma; FB-feixes de braquiesclereides; FF-feixe fibrovascular; FE-fibras endocárpicas; Me-mesocarpo; Pe-perianto; Te-tegumento. 
glabro (Figura 1C), com epiderme formada por células tabulares e cutinizadas. Abaixo da epiderme há uma região subepidérmica com várias camadas de células taníferas, de conteúdo fortemente corado pela safranina, de diferentes formatos (Figura 1D). Adjacente a região subepidérmica ocorrem feixes de braquiesclereides enfileirados entre várias camadas de células esclerenquimáticas (Figura 1D). Benarrós (2002) verificou um pericarpo complexo em $O$. bacaba Mart. constituído por uma epiderme, uma hipoderme que se esclerifica no fruto maduro e ainda feixes de esclereídes contendo corpos silicosos.

Mesocarpo fibro-carnoso, oleaginoso, de coloração amarelo-clara e quando exposto, oxida rapidamente para a coloração marrom. É também constituído por idioblastos taníferos freqüentemente agrupados entre as células parenquimáticas (Figura 1D-E), diferenciando-se claramente do epicarpo e endocarpo (Figura 1D). Estas características já foram observadas em $O$. bacaba (Benarrós, 2002) e Jubaeopsis caffra Becc. (Robertson, 1977). Entre o mesocarpo e o endocarpo há uma camada de feixes fibrovasculares (Figura 1E). Na análise dos componentes minerais (epicarpo e mesocarpo) verificou-se a presença de $0,67 \mathrm{mg} / \mathrm{g}$ de $\mathrm{Ca}$, $0,43 \mathrm{mg} / \mathrm{g}$ de $\mathrm{Mg}, 0,08 \mathrm{mg} / \mathrm{g}$ de Fe, $0,02 \mathrm{mg} / \mathrm{g} \mathrm{de} \mathrm{Cu}, 9,5 \mu \mathrm{g} / \mathrm{g}$ de $\mathrm{Zn}$ e $0,02 \mathrm{mg} / \mathrm{g}$ de Mn. Chaves \& Pechnick (1945) avaliando componentes químicos em algumas espécies vegetais, determinaram na bebida do açaí alguns constituintes minerais como: $0,034 \%$ de $\mathrm{P}_{2} \mathrm{O}_{5}, 0,028 \%$ de $\mathrm{CaO}, 0,0022 \%$ de $\mathrm{Fe}_{2} \mathrm{O}_{3}$, $0,026 \%$ de $\mathrm{SiO}_{2}$ e $0,0055 \%$ de $\mathrm{SO}_{3}$.

Endocarpo formado por vários estratos de fibras e que observados a olho nu mostram duas colorações, amareloclara e marrom, estando parcialmente aderidas ao tegumento (Figura 1D-E). A epiderme locular restringe-se a uma única fileira de células pequenas esclerificadas de paredes espessas e lúmen reduzido (Figura 1E), delimitando a região interna da parede ovariana. Murray (1973) observou em Caryota mitis Lour. que o endocarpo consiste unicamente das células da epiderme locular esclerificada no fruto maduro. Enquanto Robertson (1977) verificou a epiderme locular em Jubaeopsis caffra, como sendo uma porção do endocarpo e que este tecido se diferencia após a lignificação das paredes das células, como o observado na espécie em questão.

A semente varia de globosa a elipsóide (Figura 2A), medindo em média $13 \mathrm{~mm}$ de comprimento e $11 \mathrm{~mm}$ de diâmetro, com pesos médios de $1,1 \mathrm{~g}$ de matéria fresca e $0,6 \mathrm{~g}$ de matéria seca, que corresponde á $44 \%$ de umidade (Tabela 1). O tegumento é uma fina camada que reveste a semente, de coloração marrom-alaranjada, com várias cicatrizes longitudinais deixadas pelas fibras do endocarpo (Figura 2A). Várias camadas de células taníferas, coradas de vermelho pela safranina, com formas variando em alongadas ou achatadas constituem o tegumento (Figura 2B) externo, sendo mais espesso que o tegumento interno, com poucas camadas de células retangulares, similar a Schinus terebinthifolius Raddi, que apresenta o tegumento externo mais espesso que o interno (Carmello-Guerreiro \& Paoli, 1999). Longos feixes vasculares circundados por bainha esclerenquimática ocorrem entre as células do tegumento (Figura 2B). Uma nítida cicatriz liga o poro germinativo, situado da região basal ao ápice da semente no sentido longitudinal, que caracteriza a rafe (Figura 2C).

Endosperma abundante, ocupa toda a cavidade da semente, de coloração branco-prateada brilhante, sólido e homogêneo (Figura 2D), formado por células longas de paredes espessas (Figura 2B). O embrião mede em média 9mm de comprimento e $4 \mathrm{~mm}$ de diâmetro (Tabela 1), conforme Martin (1946) é do tipo basal capitado, característico de

TABELA 1. Valores médios de tamanho e peso dos frutos, sementes e embriões de Oenocarpus minor Mart.

\begin{tabular}{lccccccccccc}
\hline & \multicolumn{3}{c}{ Fruto } & \multicolumn{1}{c}{ Semente } & & \multicolumn{2}{c}{ Embrião } \\
\cline { 2 - 11 } & $\begin{array}{c}\text { CMP } \\
(\mathrm{mm})\end{array}$ & $\begin{array}{c}\mathrm{DM} \\
(\mathrm{mm})\end{array}$ & PMF $(\mathrm{g})$ & $\begin{array}{c}\text { CMP } \\
(\mathrm{mm})\end{array}$ & $\begin{array}{c}\mathrm{DM} \\
(\mathrm{mm})\end{array}$ & $\begin{array}{c}\text { PMF } \\
(\mathrm{g})\end{array}$ & $\begin{array}{c}\text { PMS } \\
(\mathrm{g})\end{array}$ & $\begin{array}{c}\text { UMD } \\
(\%)\end{array}$ & $\begin{array}{c}\text { CMP } \\
(\mathrm{mm})\end{array}$ & $\begin{array}{c}\text { DM } \\
(\mathrm{mm})\end{array}$ \\
\hline Média & 16 & 13 & 1,6 & 13 & 11 & 1,0 & 0,6 & 44 & 9 & 4 \\
\hline Mínimo & 12 & 11 & 1,1 & 10 & 9 & 0,7 & 0,4 & 24 & 8 & 3 \\
\hline Máximo & 19 & 16 & 2,8 & 15 & 13 & 1,7 & 1,0 & 67 & 12 & 6 \\
\hline Desvio padrão & 1,03 & 1,07 & 0,39 & 0,96 & 0,82 & 0,23 & 0,13 & 4,41 & 1,07 & 0,71 \\
\hline
\end{tabular}

CMP - comprimento; DM - diâmetro; PMF - peso da matéria fresca; PMS - peso da matéria seca; UMD - umidade; Amostragem: 100 frutos, 100 sementes e 30 embriões. 

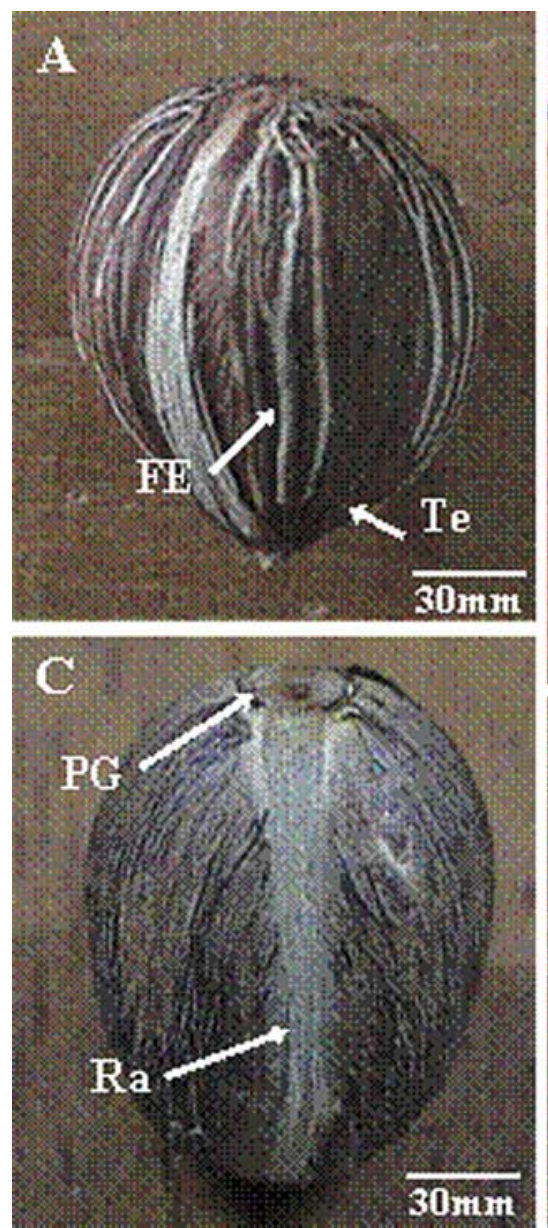
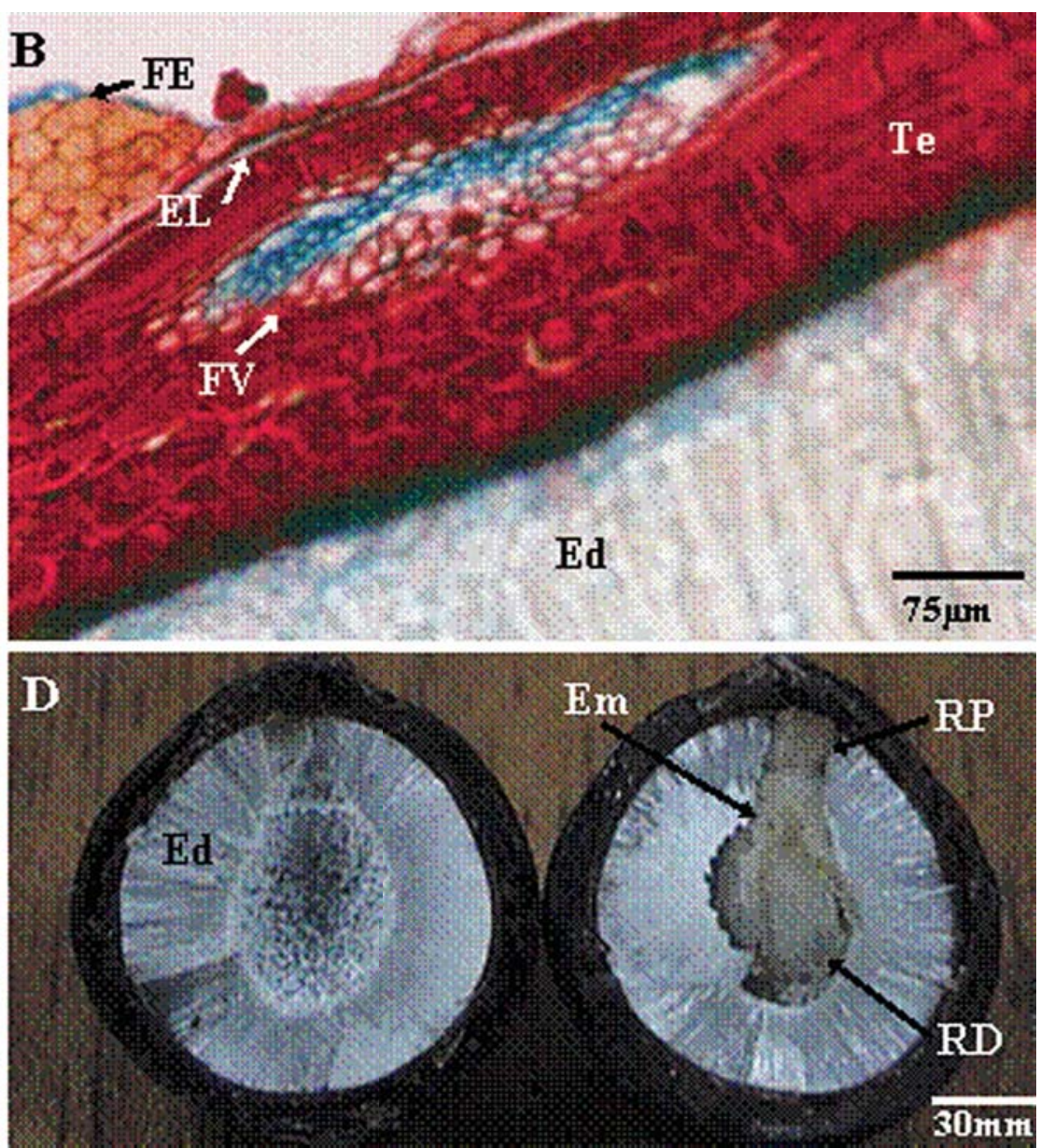

FIGURA 2. Semente de Oenocarpus minor Mart.: A-semente com detalhe das fibras endocárpicas; B-corte transversal da semente com detalhe do tegumento e endosperma; $C$-semente com detalhe do poro germinativo e da rafe; D-semente aberta longitudinalmente. Legenda: Ed-endosperma; EL-epiderme locular; Em-embrião; FV-feixe vascular; FEfibras endocárpicas; PG-poro germinativo; Ra-rafe; RD-região distal; RP-região proximal; Te-tegumento.

monocotiledôneas (Figura 2D), distinguindo-se duas regiões: a região proximal, voltada para o poro germinativo e de coloração amarelo-pálida, que oxida rapidamente quando retirado da semente, mudando para a coloração marromamarelada e a região distal de coloração amarelo-clara, em posição central na região basal (Figura 2D).

\section{CONCLUSÕES}

A descrição morfo-anatômica dos frutos e das sementes de Oenocarpus minor Mart. revela caracteres estruturais que contribuem na identificação da espécie, bem como fornece dados para posteriores estudos fenológicos e reprodutivos.

$\mathrm{O}$ estudo dos minerais trata de dados preliminares, mas relevantes devido à presença dos componentes $\mathrm{Ca}, \mathrm{Fe}, \mathrm{Mg}$, $\mathrm{Zn}, \mathrm{Cu}$ e $\mathrm{Mn}$ na espécie, havendo necessidade de futuras investigações nutricionais visando o uso destes frutos como fonte de complemento alimentar.

\section{AGRADECIMENTOS}

Ao $\mathrm{CNPq}$ pelo apoio financeiro e bolsas (PQ e IC) concedidas.

\section{REFERÊNCIAS}

AGUIAR, M.O.; MENDONÇA, M.S. Morfo-anatomia da semente de Euterpe precatoria Mart. (Palmae). Revista Brasileira de Sementes, Brasília, v.25, n.1, p.37-42, 2003.

AOAC- Association of Official Analytical Chemists. Official methods of analyses. 16.ed. Washington, 1995. 2000p. 
ARAÚJO, M.G.P.; LEITÃO, A.M.; MENDONÇA, M.S. Morfologia do fruto e da semente de inajá (Attalea maripa (Albl.) Mart.) - Palmae. Revista Brasileira de Sementes, Brasília, v.22, n.2, p.31-38, 2000.

ARAÚJO, M.G.P. Morfo-anatomia e desenvolvimento dos frutos e sementes de três espécies da subfamilia Arecoideae (Arecaceae). Manaus, 2005. 189f. Tese (Doutorado em Ciências Biológicas, área de concentração Botânica) - Instituto Nacional de Pesquisa, Universidade Federal do Amazonas, Manaus, 2005.

BENARRÓS, J.F. Morfo-anatomia do desenvolvimento do fruto e semente de Oenocarpus bacaba (Mart.) Wendl. (Arecaceae) ocorrentes na Região de Manaus-Am, Brasil. Manaus, 2002. 71f. Dissertação (Mestrado em Ciências Biológicas, área de concentração Botânica) - Instituto Nacional de Pesquisa, Universidade Federal do Amazonas, Manaus, 2002.

CARMELLO-GUERREIRO, S.M.; PAOLI, A.A.S. Morfologia e anatomia da semente de Schinus terebinthifolius Raddi (Anacardiaceae) em desenvolvimento. Revista Brasileira de Botânica, São Paulo, v.22, n.1, p.91-98, 1999.

CHAVES, J.M.; PECHNICK, E. O assaí, um dos alimentos básicos da Amazônia. Boletim Institucional de Tecnologia Alimentar, Rio de Janeiro, p.169-172, 1945.

HENDERSON, A.; SCARIOT, A. A flórula da Reserva Ducke, I: Palmae (Arecaceae). Acta Amazônica, Manaus, v.23, n.4, p.349-369, 1993.

LARA, A.B.W.H.; NAZÁRIO, G.; ALMEIDA, M.E.W.; PREGNOLATO, W. Normas analíticas do Instituto Adolfo Lutz. Métodos químicos e físicos para análise de alimentos. 2.ed., v.1. São Paulo: Instituto Adolfo Lutz, 1976. 371p.
MARTIN, A.C. The comparative internal mophology of seeds. The American Midland Naturalist, Indiana, v.36, n.3, p.513-660, 1946.

MENDONÇA, M.S. Aspectos morfológicos das sementes de algumas espécies de palmeiras (Arecaceae $=$ Palmae) da Amazônia. Manaus, 1996. 68f. Tese (Professor Titular em Anatomia vegetal) - Faculdade de Ciências Agrárias, Universidade Federal do Amazonas, Manaus, 1996.

MENEZES, C.R. Estrutura morfo-anatômica de frutos e sementes de Socratea exorrhiza (Mart.) Wendl.. (Arecaceae) ocorrentes na Região de Manaus-AM, Brasil. 2000. 57f. Dissertação (Mestrado em Ciências Biológicas, área de concentração Botânica) - Instituto Nacional de Pesquisa, Universidade Federal do Amazonas, Manaus, 2000.

MURRAY, S.G. The formation of endocarp in palms fruits. Principes, Inglaterra, v.17, p.91-102, 1973.

PANTIÑO, J.C. Microtecnia vegetal. Trilha: México, 1986. $106 \mathrm{p}$.

PAULA, J.E. Anatomia de Euterpe oleraea Mart. (Palmae da Amazônia). Acta Amazonica, Manaus, v.5, n.4, p.265278, 1975.

ROBERTSON, B.L. Morphology and development of the fruit and seed of Jubaeopsis caffra Becc. Principes, Inglaterra, v.16, p.23-31, 1977.

TOMLISON, P.B. Essays on the morphology of palms. I. Germination and the seedling. Principes, Inglaterra, v.4, n.2, p. 56-63, 1960.

UHL, N.W.; DRANSFIELD, J. Genera Palmarum: a classification of palms based on the work of Harold $E$. Moore. Kansas: Allen Press, 1987. 610p. 